\title{
Mechanical Stress Exploration Inside of Dental Filling Materials by Means of Electronic Speckle Pattern Interferometry/Shearography
}

\author{
ALINA ORMENISAN ${ }^{1}$, DANIEL TAMAS SZAVA ${ }^{1 *}$, IOAN SZAVA², CIPRIAN DALAI ${ }^{3}$ \\ ${ }^{1}$ University of Medicine and Pharmacy Tirgu Mures, Faculty of Dental Medicine, 38 Gh. Marinescu Str., 540139, Tirgu Mures, \\ Romania \\ 2 University Transylvania of Brasov, Faculty of Mechanical engineering, 29 Eroilor Blvd., 500036, Brasov, Romania \\ ${ }^{3}$ University of Oradea, Faculty of Medicine and Pharmacy, 101 Decembrie Sq., 410073, Oradea, Romania
}

\begin{abstract}
Possible causes of microleakage and microfractures of dental fillings are often in the center of many academic research and investigations. Some authors found that one important cause of microleakage is the contraction/ shrinkage of the filling materials during polymerization. The purpose of this study is to demonstrate that microcracks and consequent microleakage is influenced by mechanical stresses occurring inside of dental filling materials and at the interface of the dental cavities and dental filling materials. We also tried to evaluate the deformation of some dental filling material types during mechanical loading. Cylindrical specimens were made of differenttypes of dental filling materials, namely microhybrid composites and glass ionomer cement. Some extracted teeth were prepared with class II cavities, and filled. The lateral swelling of the tested specimens and the deformation of the filled teeth during vertical axial loading was measured with an optical method, ESPI/ Shearography.Of the tested specimen, the least deformable dental filling materials were the composite materials. During occlusal vertical loading of the filled teeth, there were found that mechanical stresses were different inside of the filling material than inside of the walls of the dental tissues, mechanical stressed being concentrated at the restoration interface. The ESPI/Shearography meth ode proved to be very useful for investigation in this field. Due to mechanical stresses accumulating at the interface of the dental filling material and the walls of the dental cavity, it is possible that later microcracks to appear due to masticatory forces.
\end{abstract}

Keywords: dental filling material, microcracks, microleakage, ESPI/Shearography

It is known that modern dental filling materials with physiognomic properties have certain deformationshrinkage during the polymerization process [1]. This is manifested in contraction of the dental filling material, which compromises the marginal adaptation of the filling material at the walls of the cavity prepared inside a certain tooth. Poor marginal adaptation in-between the two surfaces (tooth-filling material), is ultimately leading to micro leakage and appearance of secondary caries lesions [2-5].

During our dental practice we observed that poor marginal adaptation of the dental filling material was detected after a few years of use though in most cases it was undetectable by clinical methods after polishing its surface. We assume that marginal crack formation and microleakage compromising dental tissue integrity is a phenomena that installs in time during repeated masticatory cycles on the restored tooth. It is known that different filling material types are different in stiffness. This is calculated in elastic modulus, which are usually different from dental tissues [1, 6-11].

Our purpose was to measure the stiffness and to categorize some widely spread dental filling materials from this point of view.

Assumingly the least elastic material will exercise the smallest amounts of horizontal forces on the walls of the cavity during its deformation, in response of the vertical masticator forces.

We also wanted to investigate force distribution inside the walls of the dental tissues during loading.

\section{Experimental part}

Firstly to evaluate the dental filling material stiffness, there were made some cylindrical specimens which were subjected to uniaxial compression. Secondly with a parallelograph system there were prepared some mesialocclusal-distal cavities inside of some extracted molars $[6,8,11]$.

In these experiments were tested 2 types of filling materials: microhybrid composites $(A, B, C)$, respectively glass-ionomers $(D, E, F)$. From all of them were manufactured both small cylinder specimens and filled teeth assemblies (fig. 3-5).

The displacement field and deformation of the tested specimen were evaluated with ESPI/Shearography System (ISI-Sys GmbH, Germany) [6, 8, 11-13]. The system allows a high-accuracy (with some nanometers resolution) evaluation of the displacements. The principle of this optical method is based on the appearance of interferometric lines of the laser light.

The ESPI method has been designed to test and detect defects at the surface of some materials. It is a nondestructive method, which is based on the identification of the non-homogeneous gradient of deformation of the irregular or defective surface of a specimen subjected to mechanical forces. Being a precision optical method capable of identifying and examining the most detailed details, and the smallest deformation of a surface, even in the order of microns or nanometers, facilitating an extremely accurate analysis, perceiving the deformations occurring at the lowest mechanical stress, thermal, acoustics of the tested material. The principle of the 
method is based on the translation of the image (shearing) captured by a digital camera. The analyzed surface is illuminated by coherent polarized light, namely two laser diodes; light is reflected in all directions on the surface of the analyzed body. By applying and deforming the specimen, the change in the distance of two points can be measured by calculating the wavelength change of laser light.

In this sense the so-called reference plate method was applied.

With the help of the Michelson Interferometer, the image of this small, unloaded plate, superposed by shearing over the tested (loaded) specimen's image offers a good and high-sensitivity strain analysis [12,13].

The laser diodes assure a good and equal illumination of the observed surface. They are fixed on the high-stiffened polycarbonate rods (fig 1, fig 2).

The Michelson Interferometer 5 and the 4 MPX CCD cameras are disposed in normal direction to the object. The distances are given in $\mathrm{mm}[6,8,11]$.

\section{Results and discussions}

In order to establish the elasticity of the test material, was measured the specific shortening of the specimen, made of micro-hybrid composite material (table 1).

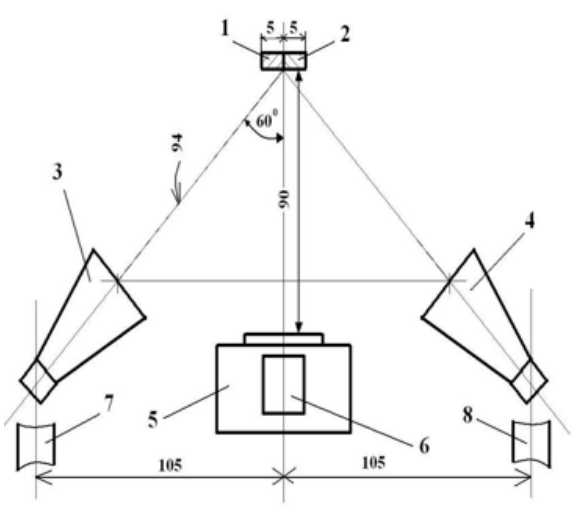

Fig.1 ESPI/Shearography System [6,8]. 1.Reference, 2.Tested specimen, 3.Laser diode, 4.Laser diode, $94 \mathrm{~mm}$ distance from the specimen, 5. Michelson Interferometer (mirror system, composed of a semi-mirror for doubling the image and phase shift mirror and shearer mirror)., 6.MPX CCD Camera, 7.Polycarbonate tube for laser diode fixation

\begin{tabular}{|c|c|c|}
\hline $\begin{array}{c}\mathrm{Fu} \\
(\mathrm{mV})\end{array}$ & $\begin{array}{c}\text { Fl } \\
(\mathrm{mV})\end{array}$ & $\begin{array}{c}\varepsilon \text { (specitic shrinkage of the sample) } \\
\qquad(\times 10-7 \mathrm{~m})\end{array}$ \\
\hline \multicolumn{3}{|c|}{ Composite A } \\
\hline 468 & 489 & 1.50 \\
\hline 473 & 514 & 1.16 \\
\hline 692 & 642 & 1.28 \\
\hline 562 & 561 & 1.13 \\
\hline \multicolumn{3}{|c|}{ Composite B } \\
\hline 246 & 270 & 1.28 \\
\hline 234 & 242 & 1.72 \\
\hline 182 & 196 & 4.2 \\
\hline 246 & 270 & 1.28 \\
\hline \multicolumn{3}{|c|}{ Composite C } \\
\hline 40 & 49 & 2.01 \\
\hline 50 & 58 & 1.96 \\
\hline 75 & 82 & 2.54 \\
\hline \multicolumn{3}{|c|}{ Cement glass 1onomer $\mathrm{D}$} \\
\hline 20 & 28 & 1.23 \\
\hline 26 & 32 & 1.32 \\
\hline 31 & 41 & 1.29 \\
\hline \multicolumn{3}{|c|}{ Cement glass 1onomer $\mathfrak{E}$} \\
\hline 23 & 26 & 1.37 \\
\hline 34 & 39 & 1.26 \\
\hline 39 & 45 & 1.82 \\
\hline \multicolumn{3}{|c|}{ Cement glass 1onomer $\mathrm{F}$} \\
\hline 70 & 83 & 1.43 \\
\hline 81 & 87 & 0.87 \\
\hline 93 & 102 & 1.21 \\
\hline
\end{tabular}

Table 1

SPECIFIC SHRINKAGE OF THE SAMPLES 


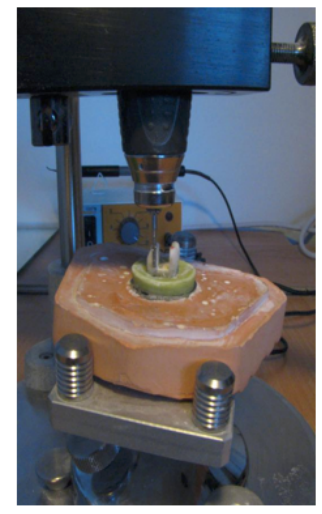

Fig 2. Preparing the cavities inside the teeth with a parallelogram. In these cavities the different filling materials were placed

Fig. 3. ESPI [14]

Fig,4. The tooth with filling material

Fig.5. Specimens made from different filing materials
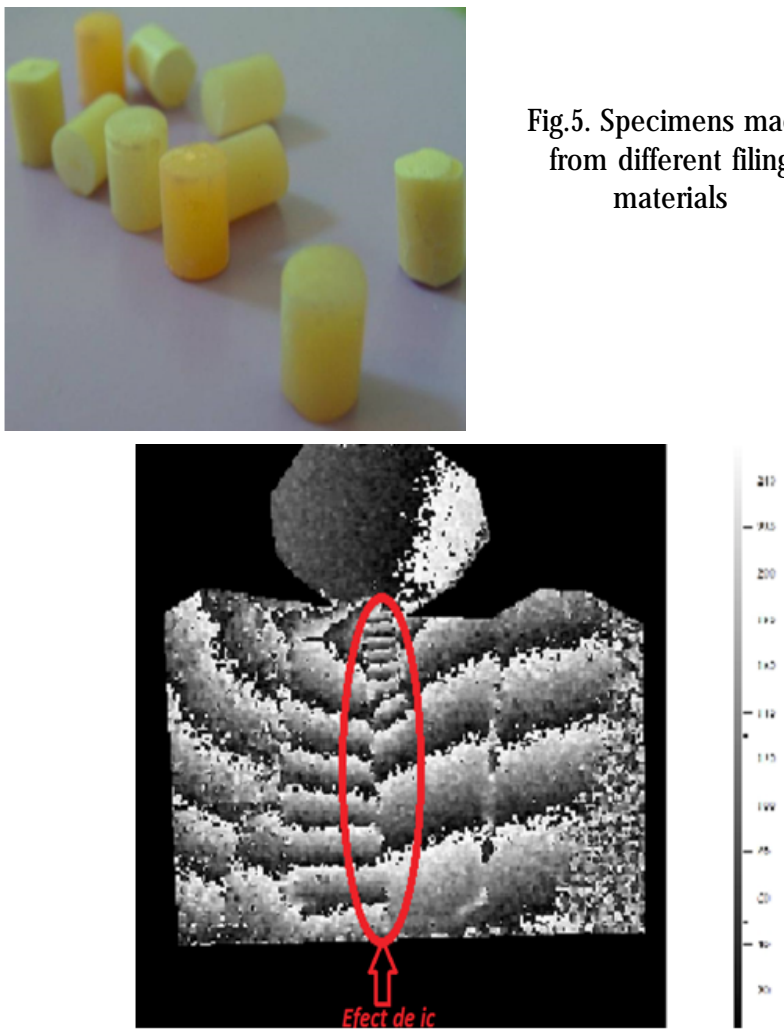

Fig.6 The way of dispersing the mechanical stresses inside the filling and the wall of the prepared tooth
- The specific shortening of the specimen for different forces applied to the specimens was calculated,

- The shortening of the specimen $\delta_{\varepsilon}=\ell_{0}-\ell_{1}[\mathrm{~mm}]$ is monitored by ESPI. The length $\ell_{0}$ at the moment of applying a force $F o, \ell_{1}$ when applying an F1 force.

- Specific shortcut $\varepsilon_{\varepsilon}=\frac{\delta_{\varepsilon}}{\ell_{0}}[-]$ is an importanthinton the elasticity of a material

- Young modulus $E=\sigma / \varepsilon$

- $\sigma$ is the developed tension on the piece

In the second stage, the filling was placed inside the tooth in the case of a Black class II cavity preparation (fig.6).

The ESPI method has been designed to test and detect defects at the surface of some materials. It is a nondestructive method, which is based on the identification of the inherent gradient of deformation of the irregular or defective surface of a specimen subjected to mechanical forces. Being a precision optical method capable of identifying and examining the most detailed details, and the smallest deformation of a surface, even in the order of microns or nanometers, facilitating an extremely accurate analysis, perceiving the deformations occurring at the lowest mechanical stress of the tested material.

Measurements must be carried out under special laboratory conditions, isolated from vibrations, on special supports, since the lower body movements can cause major measurement errors, the advantage of the optic method not to interfere with the phenomenon analyzed may be lost. During experiments these were the biggest problems we met. Although we have been able to measure specimen specific shortening, testing the modulus of elasticity of the fill material will require additional measurements.

We consider that the method is extremely useful for assessing the distribution of stress at the interface of two different materials, for the accumulation of mechanical stresses caused by inhomogeneity, and surface defects of some, small or tiny matrices, occurring at sufficiently low load forces. As far as the distribution of mechanical stresses is concerned, they differ within the filling material and the dental structure. The presence of a well-defined interface by the orientation and distribution of mechanical stress, which coincides with the interface between the dental filling material and the wall of the dental cavity, has been observed. This assumes that atthis level, the bond between the obturation material and the dentine enamel can yield over time due to the different deformations of the two materials through the mastication cycles, and suppose it is the causal factor of the cessation of the marginal closing of the obturation [14].

\section{Conclusions}

The presented method allows the evaluation of certain physical properties - in our case the mechanical elasticity of the materials to be filled with high precision.

Being a non-destructive optical method, itallows testing the phenomenon studied several times.

In the experiments presented, the greatest difficulty encountered was the physical mobilization of the specimen tested with its loading with axial compression mechanical forces that caused major measurementerrors. Due to these difficulties, in vivo measurements were dropped.

Studying the obtained images about the pattern of dispersion of mechanical forces inside and the surface of the obturations, we can mention that the method serves precious information about the mechanical behavior of 
certain types of filling materials, but also about the mechanical behavior of the type, and the shape of the dental cavity.

\section{References}

1. GHIBAN, A., GHIBAN, B., SERBAN, TN., TIGANESCU, T.V., Hot Working Behaviour of a New Dental Alloy, Mat. Plast., 53, no. 4, 2016, p.708

2. MONEA, A., et al: Odontologie of Parodontologie, Editura UMF Tg.Mures, 2004

3. ILIESCU, A., GAFAR, M.,; Cariologie si odontoterapie restauratoare, Editura Medicala, Bucuresti, 2001

4. BEHR M, ROSENTRITT M, REGNET T, LANG R, HANDEL G.: Marginal adaptation in dentin in non self adhesive universal resin cement compared with well-tried systems. Dental Materials, 2004, Volume 20, Issue 2, pp. 191-197

5. COURET, H, ,GRÉGOIRE, G. , FONTAN, F., DE PARSEVAL, PH., ARMAND, S., Electron microprobe analysis into interactions of a resinmodified composite with human dentine in vitro. C.R. Biologies, vol.327, no.1, 2004, pp.21-28

6. SZAVA, I., NECULA, R. D., GALFI, B.P., SZAVA, D., SAMOTA, I, New Methods in Bio-mechanical Experimental Investigations, Proceedings of the $50^{\text {th }}$ Annual Conference on Experimental Stress Analysis, EAN2012, June 4-7, 2012, Tábor, Czech Republic, Published by The Czech Technical University of Prague, ISBN 978-80-01-05060-6, pp. 449-456 7. GHIBAN, N; BORTUN, C. M; BORDEASU, I; GHIBAN, B; FAUR, N; CERNESCU, A; Hanganuu SC; Evaluation of Mechanical Properties by
Stereo-and Scanning Electron Microscopy of Some HeatCuring Dental Resins, MATERIALE PLASTICE, Volume: 47, Issue: 2, 2010, pp: 240243

8. SZAVA, D., SZAVA, I., VLASE, S., GALFI, B., Dental Filling Materials' Young Moduli Determination Using Espi/Shearography Method Preliminary Results -, Proceedings of the $4^{\text {th }}$ Int. Conf. COMAT 2012, DERC Publishing House, USA, ISBN 13: 978-0981730059; ISBN 10: 0981730051, pp. 18-23

9. CIAVOI, G., BECHIR, A., TIG, I., DALAl, C.,MANU, R.,Aspects Regarding The Use of Three Types of Polymers As Denture Base Materials, Mat. Plast. 53, no. 2, 2016, p.247

10. MUNTEAN, A., MESAROS, A., FESTILA, D., MOLDOVAN, M., MESAROS M., In Vitro Microleakage Evaluation Around Three Types 0, Mat. Plast. 53 ,no. 1, 2016, p.166

11. SZAVA, D., GÁLFI, B., SZAVA, I., ORBÁN, P., Research and Academic Exploration about Optimal Attitudes of Dental Filling Materials, The 10th Youth Symposium on Experimental Solid Mechanics, 25-28 May, 2011, Chemnitz University of Technology, Germany, ISBN: 978-3-94100334-7, Proceedings of Symposium, pp. 107-108 http://www.imeko.org/ publications/ysesm-2011/IMEKO-YSESM-2011-ea40.pdf

12. SUTTON, A. M., Orteu, J. J., Schreier, W. H.: Image Correlation for Shape, Motion and Deformation Measurements, Springer Verlag, 2010 13. ***User Manual and Service Instructions SE3 Shearography/ESPISystem, ISI-Sys GmbH, Kassel, Germany, 2009 14. SZAVA D. T., Lucrare de Licenta, UMF Tg. Mures, 2011

Manuscript received: 9.09 .2017 